\title{
Responding to the rising number of children living with complex chronic conditions
}

\author{
Eyal Cohen MD MSc, Hema Patel MD MSc
}

See also editorial on page 1195 and at www.cmaj.ca/lookup/doi/10.1503/cmaj.141207

$\mathrm{T}$ he Canadian health care system is undergoing substantial transformation to meet the needs of the rising number of adults, particularly older adults, with complex chronic conditions. Provinces are planning reform in primary, acute, home and long-term care for older adults in an attempt to deal more effectively, and more costeffectively, with the increasing burden presented by an older, sicker population. However, at the other end of the life cycle, a small but growing population of children has equally important, complex health needs that warrant our focus and attention.

Children with medical complexity have been defined as those with complex chronic conditions requiring specialized care, with substantial health care needs, functional limitations and high use of health resources, although definitions vary. ${ }^{1}$ These children represent less than $1 \%$ of all children, but their numbers are growing because of dramatic advances in medical and surgical care that have led to lower mortality for almost every life-threatening condition of childhood, such as extreme prematurity and complex congenital heart disease. Medical equipment and technologic advances, such as ventilator support, feeding tubes, total parenteral nutrition and transplantation have successfully prolonged the lives of children and youth with failure of the lung, gut or other organs. Consequently, a new generation of long-term survivors of childhoodonset diseases has been created, with important medical, health system and social consequences.

As with their adult counterparts, children with medical complexity need care from multiple service providers over a prolonged period. Studies have shown that the care for these children accounts for about one-third of all child health costs, ${ }^{2}$ as well as a rapidly growing proportion of pediatric hospital use, including $41 \%$ of all pediatric hospital expenditures. ${ }^{3}$ In our current health care context, children with medical complexity are at increased risk of hospital readmissions, ${ }^{4}$ medical error, ${ }^{5}$ inadequate care coordination, and consequent adverse physical and mental health outcomes for caregivers. ${ }^{6}$
Many survivors of serious childhood conditions experience life-long associated comorbidities and other sequelae of their underlying diseases. There is also "collateral damage," including disability, daily dependence on medical technology, medical fragility and long-term caregiver burnout. Social costs are high. Families report substantial stress, particularly due to financial burden, and unmet needs for health care services. In one large American survey, about half of parents of children with medical complexity reported that a family member stopped working because of their child's health.?

Structured clinical programs aiming to provide coordinated, comprehensive and familycentred care have been developed to serve this population. Programs vary somewhat in their models of care (e.g., primary care providers v. partnership between children's hospitals and community-based primary care providers), target population and team composition (e.g., physicians, nurses and/or other allied health professionals). These programs are often located within children's hospitals, but data are lacking on their effectiveness compared with a wellsupported community-based model of care.

Providing access to excellent communitybased care for children with medical complexity is challenging, but necessary. Primary care has undergone substantial reform across much of Canada with the goal of facilitating better care for people with chronic disease (e.g., by better coordination of a multidisciplinary team), but the unique developmental and social needs of chil-

\section{KEY POINTS}

- Canadian health care is transforming to care for growing populations of adults with complex medical conditions, but little attention has been paid to children with medical complexity.

- Care for children with complex medical conditions accounts for an increasing proportion of pediatric health expenditures, and these children are at risk of poor health outcomes.

- Models of innovative care for these children are emerging but have not been adapted into system-wide solutions.
Competing interests: None declared.

This article was solicited and has not been peer reviewed.

\section{Correspondence to: \\ Eyal Cohen, eyal.cohen @ sickkids.ca}

CMAJ 2014. DOI:10.1503 /cmaj.141036 
dren and youth are rarely incorporated into these changes $^{8}$ (Appendix 1, available at www.cmaj.ca /lookup/suppl/doi:10.1503/cmaj.141036/-/DC1). Some primary care providers may be insufficiently trained to manage the many relatively uncommon "orphan" childhood conditions. In many parts of the country, pediatricians may play a large role in the primary care of children with medical complexity, often in collaboration with a family physician. However, eventual transition to adult care may be challenging because it can be difficult to find a similar type of provider in the adult health sector. Further complicating matters, financial incentives to providers in Canada to care for children with medical complexity, either in the community or the hospital setting, are extremely limited.

Whereas every provincial and territorial government explicitly values the concept of homeand community-based care for children, the actual support provided (e.g., home care, respite care, special education) to families of children with medical complexity varies widely between and within regions throughout Canada. ${ }^{9}$ Even when available, funding for such services is often divided between different ministries (e.g., health, social services, education), leading to disjointed funding and planning. Proper coordination of services may be the difference between at least one parent being able to continue working and a family being forced to provide all of their child's care and to accept unemployment. Sadly, some families have had to surrender custody to child welfare societies to get the care and support they need. ${ }^{10}$

Hope remains, however, as pockets of innovation have developed across Canada. Collaborations focused on improving the delivery of care to children with medical complexity have been established within national and international pediatric organizations, and Web-based repositories of information and tools are becoming available. There is an increasing awareness that proactive, goal-directed care plans are essential for children with medical complexity, just as they are for similar adults, as are continuity, access to health care services and facilitated communication processes. Complex care programs have been established, and many are increasingly being integrated with community care settings, ${ }^{11}$ building capacity for the care of children with medical complexity beyond the walls of pediatric hospital centres. Where applicable, transitions to adult care are being facilitated through collaborative pediatric-adult programs in some specific populations, and toolkits are being created to better facilitate transitions for patients and families, as well as providers (ontracbc.ca).
However, meaningful transformation of care will depend on these innovations being adapted into system-wide solutions. We need strong advocacy and partnership with policy-makers. It is imperative that the health system response to complex chronic disease include the important needs of these children and their extended (and all-too-often exhausted) support networks of parents, families and communities. The "silver tsunami" is pushing us, very appropriately, to transform health care services to effectively meet the needs of older adults with complex chronic conditions. Children with medical complexity, while relatively small in number and quiet in voice, deserve due consideration and adaptation of services as well.

\section{References}

1. Cohen E, Kuo DZ, Agrawal R, et al. Children with medical complexity: an emerging population for clinical and research initiatives. Pediatrics 2011;127:529-38.

2. Cohen E, Berry JG, Camacho X, et al. Patterns and costs of health care use of children with medical complexity. Pediatrics 2012; 130:e1463-70.

3. Simon TD, Berry J, Feudtner C, et al. Children with complex chronic conditions in inpatient hospital settings in the United States. Pediatrics 2010;126:647-55.

4. Berry JG, Hall DE, Kuo DZ, et al. Hospital utilization and characteristics of patients experiencing recurrent readmissions within children's hospitals. JAMA 2011;305:682-90.

5. Slonim AD, LaFleur BJ, Ahmed W, et al. Hospital-reported medical errors in children. Pediatrics 2003;111:617-21.

6. Lach LM, Kohen DE, Garner RE, et al. The health and psychosocial functioning of caregivers of children with neurodevelopmental disorders. Disabil Rehabil 2009;31:607-18.

7. Kuo DZ, Cohen E, Agrawal R, et al. A national profile of caregiver challenges among more medically complex children with special health care needs. Arch Pediatr Adolesc Med 2011;165: 1020-6.

8. Miller AR, Recsky MA, Armstrong RW. Responding to the needs of children with chronic health conditions in an era of health services reform. CMAJ 2004; 171:1366-7.

9. Peter E, Spalding K, Kenny N, et al. Neither seen nor heard: children and homecare policy in Canada. Soc Sci Med 2007;64: 1624-35.

10. Annual report 2012-2013 update. Ministry of Children and Youth Services. Toronto: Ombudsman Ontario; 2014. Available: https://ombudsman.on.ca/Investigations/SORT-Investigations /Completed/Children-with-special-needs---em-Between-a-Rock-an /Case-update---Annual-Report-2012-2013.aspx (accessed 2014 Sept. 29).

11. Cohen E, Bruce-Barrett C, Kingsnorth S, et al. Integrated complex care model: lessons learned from inter-organizational partnership. Healthc $Q 2011$; 14:64-70.

Affiliations: Division of Pediatric Medicine (Cohen), Department of Pediatrics \& Child Health Evaluative Sciences, The Hospital for Sick Children, University of Toronto; Institute of Health Policy (Cohen), Management \& Evaluation, University of Toronto, Toronto, Ont.; CanChild Centre for Childhood Disability Research (Cohen), McMaster University, Hamilton, Ont.; Division of General Pediatrics (Patel), Montreal Children's Hospital; Department of Pediatrics (Patel), McGill University, Montréal, Que.

Contributors: Both authors drafted and revised the article, approved the version submitted for publication and agree to act as guarantors of the work.

Acknowledgements: The authors thank Jeremy Friedman, Julia Orkin and Tammie Dewan for their thoughtful comments on this manuscript. 